\title{
Aromatherapy alleviates endothelial dysfunction of medical staff after night-shift work: preliminary observations
}

\author{
Kenei Shimada ${ }^{1}$, Shota Fukuda ${ }^{1}$, Kumiko Maeda ${ }^{1}$, Toshihiro Kawasaki ${ }^{1}$, Yasushi Kono ${ }^{1}$, Satoshi Jissho ${ }^{1}$, \\ Haruyuki Taguchi ${ }^{1}$, Minoru Yoshiyama ${ }^{2}$ and Junichi Yoshikawa ${ }^{1}$
}

Night-shift work causes mental stress and lifestyle changes, and is recognized as a risk of cardiovascular diseases associated with impaired endothelial function. Aromatherapy is becoming popular as a complementary therapy that is beneficial for mental relaxation. The purpose of this study was to investigate the effect of aromatherapy on the endothelial function of medical staff after night-shift work. This study consisted of 19 healthy medical personnel (19 men, mean age $32 \pm 7$ years), including 11 physicians and 8 technicians. Aromatherapy was performed for $30 \mathrm{~min}$ by inhalation of the essential oil of lavender. Flow-mediated dilation (FMD) of the brachial artery was measured three times in each subject: on a regular workday, and after night-shift work before and immediately after aromatherapy. A control study was performed to assess the effect of a 30-min rest without aromatherapy. The mean value of sleep time during night-shift work was $3.3 \pm 1.3 \mathrm{~h}$. FMD after night-shift work was lower than on a regular workday (10.4 \pm 1.8 vs. $12.5 \pm 1.7 \%, P<0.001)$, which improved after aromatherapy

(11.8 $\pm 2.5 \%, P=0.02$ vs. before aromatherapy). FMD was stable in the control study $(10.1 \pm 1.9$ vs. $10.1 \pm 2.2 \%, P=0.9)$. This study demonstrated that night-shift work impaired endothelial function in medical staff, an effect that was alleviated by short-term aromatherapy.

Hypertension Research (2011) 34, 264-267; doi:10.1038/hr.2010.228; published online 25 November 2010

Keywords: aromatherapy; endothelium; night-shift work

\section{INTRODUCTION}

An important aspect of the work environment of medical staff is that they are required to work rotating night shifts. Night-shift work disrupts the normal biological and/or social diurnal rhythms, which are factors in cardiovascular disease, ${ }^{1,2}$ as well as in a widening variety of other chronic diseases, including glucose intolerance, ${ }^{3,4}$ hypertension $^{5,6}$ and depression. ${ }^{7,8}$ Endothelium function, which is strongly associated with the onset and development of cardiovascular disease and its risk factors, ${ }^{9-11}$ has been shown to be impaired after night-shift work. ${ }^{12}$ There is a need for therapeutic options to alleviate the negative impact of working night shifts on the health of medical personnel.

Aromatherapy is increasingly recognized as a complementary therapy, leading to the promotion of comfort and relaxation, relief of pain, and the management of stress. ${ }^{13-15}$ The main action of aromatherapy is relaxation, under the control of parasympathetic nerves, as well as sedative and anticonvulsive actions on the nervous system. With regard to the association between psychological factors and pathophysiological systems, ${ }^{16}$ previous studies have suggested the beneficial effect of aromatherapy on antioxidative systems, ${ }^{17,18}$ as well as endothelial function. ${ }^{19}$ The purpose of this study was, therefore, to investigate the impact of 30-min aromatherapy on the endothelial function of medical staff after night-shift work.

\section{METHODS}

Study population

This study was approved by the Institutional Review Board of the Osaka Ekisaikai Hospital. Written informed consent for participation was obtained for all subjects. This study consisted of 19 healthy medical staff ( 19 men, mean age $32 \pm 7$ years), including 11 physicians and 8 technicians. All subjects had no history of cardiovascular disease or symptoms and had normal results on their echocardiographic examinations. Endothelial function was examined at approximately 0900 hours in each subject at the following time points: (1) on a regular day without previous night-shift work (baseline), and (2) before and (3) after a 30-min rest with aromatherapy after working a night shift. Aromatherapy-inhalation of lavender essential oil (four oil drops diluted with $20 \mathrm{ml}$ hot water)—was performed for $30 \mathrm{~min}$. The control study was performed to assess the effect of the 30-min rest without aromatherapy.

Brachial artery flow-mediated dilation (FMD)

Endothelial function was evaluated by measuring FMD of the brachial artery according to the guidelines of the International Brachial Artery Reactivity Task

${ }^{1}$ Department of Medicine, Cardiovascular Division, Osaka Ekisaikai Hospital, Osaka, Japan and ${ }^{2}$ Department of Internal Medicine and Cardiology, Osaka City University School of Medicine, Osaka, Japan

Correspondence: Dr S Fukuda, Department of Medicine, Cardiovascular Division, Osaka Ekisaikai Hospital, 2-1-10 Honden, Nishi-ku, Osaka 550-0022, Japan.

E-mail: h-syouta@mve.biglobe.ne.jp

Received 5 April 2010; revised 22 July 2010; accepted 24 August 2010; published online 25 November 2010 
Force. ${ }^{20}$ Ultrasound examination was performed with a Vivid 7 (GE Medical System, Milwaukee, WI, USA) equipped with a $7-12-\mathrm{MHz}$ linear-array scanner. The subjects remained supine for $30 \mathrm{~min}$ with the arm in a comfortable position before imaging of the brachial artery. Breakfast was not permitted before the examination. A longitudinal image of the right brachial artery proximal to the antecubital fossa was obtained. Gain and compression controls, as well as the time-gain compensation settings, were optimized for image quality. FMD was determined as the maximum increase in the diameter of the brachial artery during reactive hyperemia created by an inflated cuff ( $200 \mathrm{~mm} \mathrm{Hg}$ for $5 \mathrm{~min}$ ) on the upper arm, proximal to the measurement site. Arterial diameter was measured in millimeters from the leading edge of the intima interface of the near wall to the leading edge of the intima interface of the far wall. The image was recorded continuously from $30 \mathrm{~s}$ before to $2 \mathrm{~min}$ after cuff deflation. FMD was calculated as the ratio of brachial artery diameter after reactive hyperemia to the baseline diameter and was expressed as a percentage change.

After a 15-min rest period, nitroglycerin-mediated vasodilation (a marker of endothelium-independent vasodilation) was measured 5 min after administration of sublingual nitroglycerin $(0.4 \mathrm{mg})$. This parameter was calculated in an analogous manner to FMD measurement.

\section{Statistical analysis}

Values are expressed as mean \pm s.d. Comparisons between 30 min of rest with and without aromatherapy were made with a paired $t$-test. Repeated-measures analysis of variance was used to compare three time points (control, and before and after the 30-min rest) in the studies with and without aromatherapy. When differences were found, any two points were compared using a paired $t$-test with the Bonferroni correction. Linear regression was used for correlation of variables of interest. Differences were considered statistically significant, with $P<0.05$.

We examined the inter- and intra-observer variation of the FMD measurement. Two expert sonographers who had $>5$ years of experience in echocardiography (with approximately 50 FMD examinations) performed the FMD examinations. Inter- and intra-observer variation in measurement of FMD was determined by analysis of 10 random images by two independent blinded observers, and by the same observer at two different time points. The results were analyzed by both least-squares-fit linear regression analysis and the BlandAltman method.

\section{RESULTS}

Baseline measurement of endothelial function, in relationship with clinical characteristics, is shown in Tables 1 and 2. The average duration of night-shift work was $7.9 \pm 6.3$ years, ranging from 0.5 to 21.5 years, and the mean number of night shifts per month was $5.1 \pm 2.5$ times the level observed at the start of the study. The mean values of sleeping time during night shifts at the examinations with and without aromatherapy were $3.3 \pm 1.3$ and $3.2 \pm 0.9 \mathrm{~h}$, respectively $(P=0.7)$. The mean values of total cholesterol and triglyceride were $168.0 \pm 25.4$ and $105.6 \pm 63.3 \mathrm{mg} \mathrm{dl}^{-1}$, respectively.
The results of FMD measurements with and without aromatherapy are summarized in Figure 1. Repeated-measures analysis of variance showed significant differences in FMD at three time points (all $P<0.001)$. With aromatherapy, FMD after night-shift work was lower than that on a regular workday $(10.4 \pm 1.8$ vs. $12.5 \pm 1.7 \%$, $P<0.001)$; this parameter improved after $30 \mathrm{~min}$ of rest with aromatherapy $(11.8 \pm 2.5 \%, P=0.02$ vs. before aromatherapy). On the other hand, $30 \mathrm{~min}$ of rest without aromatherapy did not increase FMD $(10.1 \pm 1.9$ vs. $10.1 \pm 2.2 \%, P=0.9)$.

When the values of FMD were compared between with and without aromatherapy conditions, similar values were obtained after nightshift work before the 30-min rest $(P=0.5)$. In contrast, FMD after the 30 -min rest with aromatherapy was significantly greater than among those subjects who did not undergo aromatherapy $(P=0.02)$.

Nitroglycerin-induced vasodilation showed no significant differences among the three time points with $(P=0.8)$ and without $(P=0.1)$ aromatherapy: baseline $(12.3 \pm 2.9 \%)$, before and after the 30 -min rest with aromatherapy $(14.9 \pm 4.3$ vs. $13.0 \pm 3.4 \%)$, and before and after the 30 -min rest without aromatherapy $(12.0 \pm 1.9$ vs. $10.7 \pm 2.1 \%)$. The results of the hemodynamics and laboratory data with and without aromatherapy are summarized in Tables 1 and 2, respectively. There were no differences in any parameters at the three different time points, examined in both examinations, except for epinephrine in the examinations with aromatherapy. The value of epinephrine after the 30 -min rest with aromatherapy was significantly lower than the values observed at baseline and pre-aromatherapy (both $P<0.05$, Table 1). In contrast, there were no significant changes in epinephrine at any of the three time points in the examinations without aromatherapy $(P=0.3$, Table 2).

An excellent correlation was observed between inter- and intraobserver ( $r=0.98$ and 0.98 , respectively) FMD measurement variation. According to the Bland-Altman method, inter- and intra-observer variation in FMD measurements was 0.16 and $0.13 \%$, respectively.

\section{DISCUSSION}

This study demonstrated that endothelial function was reduced in medical staff after night-shift work. This transient endothelial dysfunction was alleviated by short-term lavender aromatherapy.

A healthy endothelium releases nitric oxide and maintains vascular tone in the prevention of the initiation and development of atherosclerotic complications. However, night-shift work causes sleep deprivation and inevitable mental stress, resulting in a disturbance in the normal biological and/or social diurnal rhythms. Notably, Amir et al. ${ }^{12}$ reported that FMD, as a marker of endothelial function, was reduced after night-shift work. Furthermore, an epidemiological study reported an increased risk of cardiovascular disease in shift workers. ${ }^{1}$

Table 1 Hemodynamics and laboratory data at baseline, before and after the 30-min rest with aromatherapy

\begin{tabular}{|c|c|c|c|c|}
\hline & \multirow[b]{2}{*}{ Baseline } & \multicolumn{2}{|c|}{ 30-min rest } & \multirow[b]{2}{*}{$\mathrm{P}$-value } \\
\hline & & Before & After & \\
\hline Heart rate, beats $\min ^{-1}$ & $58.8 \pm 5.2$ & $60.2 \pm 8.7$ & $55.6 \pm 8.5$ & 0.2 \\
\hline Systolic blood pressure, mm Hg & $119.6 \pm 12.0$ & $122.7 \pm 10.9$ & $118.3 \pm 7.8$ & 0.4 \\
\hline Diastolic blood pressure, $\mathrm{mm} \mathrm{Hg}$ & $71.0 \pm 8.4$ & $75.2 \pm 7.7$ & $71.1 \pm 6.0$ & 0.2 \\
\hline Glucose, $\mathrm{mg} \mathrm{dl}^{-1}$ & $98.3 \pm 8.4$ & $95.7 \pm 6.2$ & $97.6 \pm 5.1$ & 0.5 \\
\hline Epinephrine, ng ml-1 & $0.015 \pm 0.015$ & $0.022 \pm 0.020$ & $0.003 \pm 0.010^{*}$ & $<0.001$ \\
\hline Norepinephrine, $\mathrm{ng} \mathrm{ml}^{-1}$ & $0.27 \pm 0.08$ & $0.25 \pm 0.07$ & $0.25 \pm 0.07$ & 0.7 \\
\hline
\end{tabular}

The last column shows overall $P$-values from the repeated-measures analysis of variance.

${ }^{*} P<0.05$ vs. baseline and pre-aromatherapy. 
Table 2 Hemodynamics and laboratory data at baseline, before and after the 30-min rest without aromatherapy

\begin{tabular}{|c|c|c|c|c|}
\hline & \multirow[b]{2}{*}{ Baseline } & \multicolumn{2}{|c|}{ 30-min rest } & \multirow[b]{2}{*}{ P-value } \\
\hline & & Before & After & \\
\hline Systolic blood pressure, $\mathrm{mm} \mathrm{Hg}$ & $119.6 \pm 12.0$ & $123.2 \pm 11.3$ & $117.9 \pm 9.4$ & 0.3 \\
\hline Diastolic blood pressure, $\mathrm{mm} \mathrm{Hg}$ & $71.0 \pm 8.4$ & $74.9 \pm 8.8$ & $71.8 \pm 8.9$ & 0.3 \\
\hline Glucose, $\mathrm{mg} \mathrm{dl}^{-1}$ & $98.3 \pm 8.4$ & $98.5 \pm 10.7$ & $97.7 \pm 4.1$ & 0.9 \\
\hline
\end{tabular}

The last column shows overall $P$-values from the repeated-measures analysis of variance.

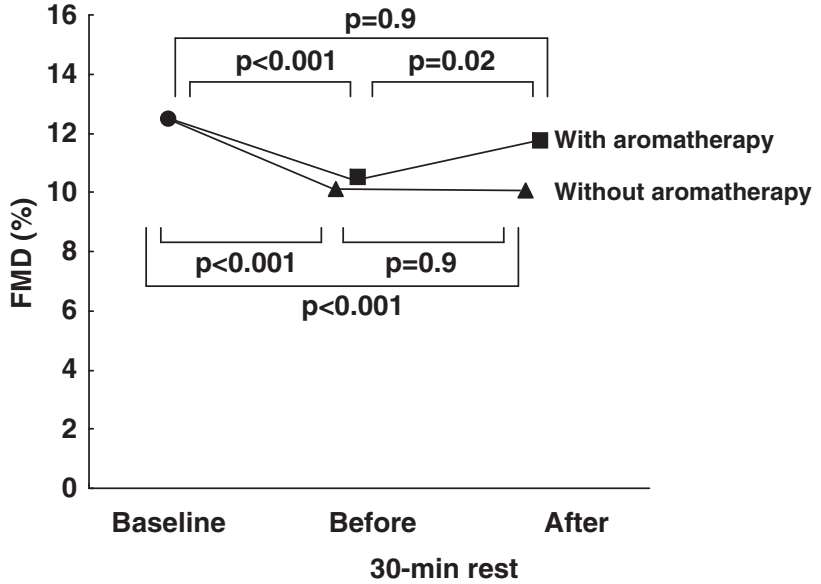

Figure 1 Values of FMD on a regular day without previous night-shift work (baseline, ), and a day after night-shift work before and after the 30-min rest with aromatherapy $(\boldsymbol{\square})$. The examination after the 30-min rest was repeated without aromatherapy $(\mathbf{\Delta})$.

Kawachi et al. ${ }^{2}$ also found that 6 or more years of shift work was associated with the risk of cardiovascular disease in female nurses. Several risk factors were exacerbated by night-shift work. ${ }^{3-8}$ However, elimination of night-shift work is unlikely to be possible for most medical staff, although reduction in the frequency and duration of shifts is recommended. ${ }^{1,21}$

Aromatherapy is a relatively inexpensive way to reduce anxiety that does not involve side effects. Based on the association between psychological factors and pathophysiological systems, ${ }^{16}$ the benefits of aromatherapy on physical systems have been investigated. ${ }^{17-19}$ Atsumi et al. ${ }^{17,18}$ demonstrated increases in free radical scavenging activity and decreases in cortisol levels with the use of aromatherapy. Shiina et al. ${ }^{19}$ measured coronary flow reserve and suggested that short-term aromatherapy improved coronary endothelial function. In the present study, endothelial function was reduced after night-shift work; this effect was alleviated by short-term lavender aromatherapy. A similar transient endothelial dysfunction was observed in association with several factors such as hyperglycemia, ${ }^{22}$ hypertriglyceridemia, ${ }^{23}$ mental stress ${ }^{24}$ and smoking. ${ }^{25}$ Such transient but frequent endothelial dysfunction potentially promotes the pathogenesis of early-stage atherosclerosis and the development of cardiovascular disease. Therefore, considering the pleasant, inexpensive and noninvasive nature of aromatherapy, it represents an attractive strategy for the alleviation of endothelial dysfunction in medical staff after working night shifts.

\section{Study limitations}

There were several limitations in this study. First, the study population was relatively small $(n=19)$. In fact, there were no significant relationships between baseline-FMD value and age $(P=0.1)$, duration $(P=0.2)$ or monthly number $(P=0.8)$ of night shifts. Thus, the impact of the intensity/accumulation of night shifts on the results of this study was unclear. Moreover, only male medical personnel were included in this study because menstrual cycle in women might have influenced the results of FMD measurements. ${ }^{26,27}$ Further investigation was necessary to clarify whether similar results were observed in women. In addition, this study was focused on the short-term effect of aromatherapy on endothelial dysfunction after night-shift work. Further study with a much larger population during long-term follow-up should be done to confirm the results of this study.

Ideally, the sonographer who performed the FMD examinations should be blinded to other patients' information. However, the smell of lavender oil was difficult to mask, and an odorless compound was easily recognized as a placebo by subjects and the FMD sonographer. In addition, we used lavender aromatherapy because lavender is one of the common essential oils used for aromatherapy. It is possible that other oils could be more effective at improving endothelial function.

Finally, the decrease in blood pressure after the 30-min rest with aromatherapy might have affected the results of this study. However, this decrease did not reach statistical significance $(122.7 \pm 10.9$ to $118.3 \pm 7.8 \mathrm{~mm} \mathrm{Hg}, P=0.4$ ) (Table 1 ). Moreover, a similar change was observed in the group with the 30-min rest without aromatherapy, from $123 \pm 11.3$ to $117.9 \pm 9.4 \mathrm{~mm} \mathrm{Hg}$ (Table 2), although the values of FMD were stable after the 30 -min rest without aromatherapy. Therefore, the improvement in endothelial function after aromatherapy might be independent of the hemodynamic changes. Further investigation should be performed to clarify this point.

\section{Conclusions}

This study demonstrated that night-shift work impaired endothelial function in medical staff, an effect that was alleviated by short-term aromatherapy.

\section{CONFLICT OF INTEREST}

The authors declare no conflict of interest.

1 Olsen 0, Kristensen TS. Impact of work environment on cardiovascular diseases in Denmark. J Epidemiol Community Health 1991; 45: 4-9, discussion 9-10.

2 Kawachi I, Colditz GA, Stampfer MJ, Willett WC, Manson JE, Speizer FE, Hennekens $\mathrm{CH}$. Prospective study of shift work and risk of coronary heart disease in women. Circulation 1995; 92: 3178-3182. 
3 Spiegel K, Leproult R, Van Cauter E. Impact of sleep debt on metabolic and endocrine function. Lancet 1999; 354: 1435-1439.

4 Kawakami N, Araki S, Takatsuka N, Shimizu H, Ishibashi H. Overtime, psychosocial working conditions, and occurrence of non-insulin dependent diabetes mellitus in Japanese men. J Epidemiol Community Health 1999; 53: 359-363.

5 Yamasaki F, Schwartz JE, Gerber LM, Warren K, Pickering TG. Impact of shift work and race/ethnicity on the diurnal rhythm of blood pressure and catecholamines. Hypertension 1998; 32: 417-423.

6 Suwazono Y, Dochi M, Sakata K, Okubo Y, Oishi M, Tanaka K, Kobayashi E, Nogawa K. Shift work is a risk factor for increased blood pressure in Japanese men: a 14-year historical cohort study. Hypertension 2008; 52: 581-586.

7 Ruggiero JS. Health, work variables, and job satisfaction among nurses. J Nurs Admin 2005; 35: 254-263.

8 Saijo Y, Ueno T, Hashimoto Y. Twenty-four-hour shift work, depressive symptoms, and job dissatisfaction among Japanese firefighters. Am J Ind Med 2008; 51: 380-391.

9 Anderson TJ. Assessment and treatment of endothelial dysfunction in humans. J Am College Cardiol 1999; 34: 631-638.

10 Patti G, Pasceri V, Melfi R, Goffredo C, Chello M, D'Ambrosio A, Montesanti R, Di Sciascio G. Impaired flow-mediated dilation and risk of restenosis in patients undergoing coronary stent implantation. Circulation 2005; 111: 70-75.

11 Cortigiani L, Rigo F, Gherardi S, Sicari R, Galderisi M, Bovenzi F, Picano E. Additional prognostic value of coronary flow reserve in diabetic and nondiabetic patients with negative dipyridamole stress echocardiography by wall motion criteria. J Am College Cardiol 2007; 50: 1354-1361.

12 Amir O, Alroy S, Schliamser JE, Asmir I, Shiran A, Flugelman MY, Halon DA, Lewis BS. Brachial artery endothelial function in residents and fellows working night shifts. Am J Cardiol 2004; 93: 947-949.

13 Eisenberg DM, Kessler RC, Foster C, Norlock FE, Calkins DR, Delbanco TL. Unconventional medicine in the United States. Prevalence, costs, and patterns of use. N Eng/ J Med 1993; 328: 246-252.

14 Louis M, Kowalski SD. Use of aromatherapy with hospice patients to decrease pain, anxiety, and depression and to promote an increased sense of well-being. Am J Hospice Palliat Care 2002; 19: 381-386.

15 Muzzarelli L, Force M, Sebold M. Aromatherapy and reducing preprocedural anxiety: a controlled prospective study. Gastroenterol Nurs 2006; 29: 466-471.
16 Rozanski A, Blumenthal JA, Kaplan J. Impact of psychological factors on the pathogenesis of cardiovascular disease and implications for therapy. Circulation 1999; 99: 2192-2217.

17 Atsumi T, Tonosaki K. Smelling lavender and rosemary increases free radical scavenging activity and decreases cortisol level in saliva. Psychiatry Res 2007; 150: 89-96.

18 Atsumi T, Tonosaki K, Fujisawa S. Salivary free radical-scavenging activity is affected by physical and mental activities. Oral Dis 2008; 14: 490-496.

19 Shiina Y, Funabashi N, Lee K, Toyoda T, Sekine T, Honjo S, Hasegawa R, Kawata T, Wakatsuki Y, Hayashi S, Murakami S, Koike K, Daimon M, Komuro I. Relaxation effects of lavender aromatherapy improve coronary flow velocity reserve in healthy men evaluated by transthoracic Doppler echocardiography. Int J Cardiol 2008; 129: 193-197.

20 Corretti MC, Anderson TJ, Benjamin EJ, Celermajer D, Charbonneau F, Creager MA Deanfield J, Drexler H, Gerhard-Herman M, Herrington D, Vallance P, Vita J, Vogel R. Guidelines for the ultrasound assessment of endothelial-dependent flow-mediated vasodilation of the brachial artery: a report of the International Brachial Artery Reactivity Task Force. J Am College Cardiol 2002; 39: 257-265.

21 Harma M. Ageing, physical fitness and shiftwork tolerance. Appl Ergon 1996; 27: 25-29.

22 Fujimoto K, Hozumi T, Watanabe H, Tokai K, Shimada K, Yoshiyama M, Homma S, Yoshikawa J. Acute hyperglycemia induced by oral glucose loading suppresses coronary microcirculation on transthoracic Doppler echocardiography in healthy young adults. Echocardiography (Mount Kisco, NY) 2006; 23: 829-834.

23 Vogel RA, Corretti MC, Plotnick GD. Effect of a single high-fat meal on endothelial function in healthy subjects. Am J Cardiol 1997; 79: 350-354.

24 Ghiadoni L, Donald AE, Cropley M, Mullen MJ, Oakley G, Taylor M, O'onnor G, Betteridge J, Klein N, Steptoe A, Deanfield JE. Mental stress induces transient endothelial dysfunction in humans. Circulation 2000; 102: 2473-2478.

25 Giannini D, Leone A, Di Bisceglie D, Nuti M, Strata G, Buttitta F, Masserini L, Balbarini A. The effects of acute passive smoke exposure on endothelium-dependent brachial artery dilation in healthy individuals. Angiology 2007; 58: 211-217.

26 Lieberman EH, Gerhard MD, Uehata A, Walsh BW, Selwyn AP, Ganz P, Yeung AC, Creager MA. Estrogen improves endothelium-dependent, flow-mediated vasodilation in postmenopausal women. Ann Intern Med 1994; 121: 936-941.

27 Hashimoto M, Akishita M, Eto M, Ishikawa M, Kozaki K, Toba K, Sagara Y, Taketani Y, Orimo $\mathrm{H}$, Ouchi Y. Modulation of endothelium-dependent flow-mediated dilatation of the brachial artery by sex and menstrual cycle. Circulation 1995; 92: 3431-3435. 